\title{
Organizational dynamic embeddedness and external shocks: The impact of financial and recession crises in strategic networks of the global pharmaceutical industry
}

\author{
ELIO SHIJAKU, ${ }^{1}$ MARTIN LARRAZA-KINTANA, ${ }^{2}$ AND AINHOA URTASUN-ALONSO ${ }^{2}$ \\ ${ }^{1}$ Departament d'Economia de l'Empresa, Facultat d'Economia i Empresa, Edifici B, Universitat \\ Autònoma de Barcelona, 08193, Bellaterra (Cerdanyola del Vallès), Catalonia, Spain; \\ and ${ }^{2}$ Departament de Gestión de Empresas, Universidad Pública de Navarra, Campus de Arrosadía, \\ 31006, Pamplona, Navarre, Spain
}

Received 16 November 2015; revised 24 February 2016; accepted 25 February 2016

\begin{abstract}
We analyze the global pharmaceutical industry network using a unique database that covers strategic transactions (i.e., alliance, financing and acquisition collaborations) for the top 90 global pharmaceutical firms and their ego-network partnerships totaling 4735 members during 1991-2012. The article explores insights on dynamic embeddedness analysis under network perturbations by exploring core and full networks' behavior during the global financial crisis of 2007-2008 and the subsequent global and Eurozone recessions of 2009-2012. We introduce and test literature grounded hypotheses as well as report network visualizations and nonparametric tests that reveal important discrepancies in both network types before and after the financial crisis offset. We observe that firms in core and full networks behave differently, with smaller top pharmaceutical firms of core networks particularly being affected by the crises, potentially due to a collaboration reduction with bigger top pharmaceuticals. On the other hand, big pharmaceuticals in full networks maintain their centrality position as a possible consequence of their strategic collaborations not only with other similarly sized firms but also due to their connections with subsidiaries and other private entities present in the total sample. Our results confirm the significant dynamicity reduction during financial crisis and recession periods for core and full networks, and highlight the importance that exogenous factors as well as network types play in centrality-based dynamic longitudinal network analysis. (C) 2016 Wiley Periodicals, Inc. Complexity 21: 602-621, 2016
\end{abstract}

Key Words: longitudinal social network; strategic transaction; dynamicity; dynamic embeddedness; pharmaceutical industry 


\section{INTRODUCTION}

0 rganizations often engage in clusters of collaborations forming complex networks of a dynamic nature. This dynamic complexity is crucial as it provides an important area to study the behavior of organizations upon which recent literature has gained new learning insights via complex computational analysis. These insights have involved the capture of organizational dynamics in a longitudinal setting, where collaborative networks are observed by focusing on the contribution that each network member (i.e., actor) provides to the overall network structure and stability [1-3]. Particularly insightful is the combination of both static and dynamic network topologies resulting in studies that shed light on both endogenous and exogenous network perturbations, with a special interest in capturing actor's contribution to any given network dynamics [4] (Hossein et al., 2013). This actor-level approach, embodied by the concept of dynamicity, has enabled researchers to study the effect of specific critical events (i.e., perturbations) that dramatically alter the structure of the longitudinal network [5].

Traditional longitudinal social network analysis has been mainly focused on dyadic (i.e., interactions between only two actors) computational approaches, often neglecting simultaneous interactions that a firm has with multiple partners at any given time [6,7]. Even studies on structural embeddedness that consider constellation analyses (i.e., interactions between more than two actors) have missed out the relevance of specific actors' influence by purposefully focusing on a specific type of collaboration. Often, as it is the case, embeddedness-based studies have relied on strategic collaborations such as alliances [8-10] neglecting other collaborations of equal importance to network dynamic behavior.

Our study provides additional insights on dynamic network evolution by considering a multitude of strategic transactions between organizations including alliance, acquisition and financing collaborations that provide an enhanced picture of the "constellation" view in state-ofthe-art social network analysis. We do so by analyzing strategic transactions in an industry of strategic importance such as the global pharmaceutical industry, and a longitudinal setting that enhances the chances of understanding dynamic behavior of organizations. Our empirical analysis is based on the novel concept of "dynamic embeddedness" defined as the individual actor's structural positions' variability in a longitudinal network compared to its structural position in an aggregated network[5]. In particular, we claim that macro-level exogenous shocks, such as the global financial crisis of 2007-2008 and the subsequent global as well as the more local Eurozone recessions during 2009-2012, might have a significant impact on firm-level measures of dynamic embeddedness within a specific network. Critical to this proposition is the idea that exogenous event impacts on a specific organization can be transmitted to any other connected member. Supporting this claim, our findings show a significant reduction of firm-level degree of dynamicity within networks, after crisis and during recession periods, highlighting the importance that exogenous factors as well as network types play in centrality-based dynamic longitudinal network analysis. To our knowledge, this is one the first attempts to analyze the effects of exogenous shocks on interfirm dynamic embeddedness.

The present article first develops a theoretical framework that serves as the substrate for testing hypotheses on both strategic collaborations between the top global pharmaceutical firms and their connections with other firms and institutions. It lately provides detailed and finegrained empirical tests that include computational network visualizations, Kernel density estimates, revised longitudinal data estimations to increase statistical robustness, as well as ANOVA tests. These methods coupled, with the inclusion of necessary descriptive data, provide an enhanced view of the critical impact that large exogenous perturbations such as global crises have on dynamic longitudinal networks between top-level actors and their partnering members in the global pharmaceutical industry.

\section{THEORETICAL FRAMEWORK}

To understand the timing of strategic transactions' influence on firm's dynamic embeddedness in a specific network, we build on three complementary theoretical lenses: longitudinal social network analysis, embeddedness and strategic transactions. Social networks have been defined as relational structures formed by interactions between social actors where each individual is represented by a node, and a tie between two nodes represents whether an interaction has occurred or a relationship exists between the individuals during the observation time $[2,11]$.

\subsection{Evolutionary social network dynamics}

Most social networks can be considered dynamic as their structure tends to evolve gradually, due to frequent changes in activity and interaction between individuals (Newman and Park, 2003), and relations between actors may rise or decay over time thereby altering the network structure they continuously form [11-15] (Lazega et al. 2009). Thus, actors inside a dynamic network are highly mobile as their relationships and positional structure continuously change hence, network dynamics is intrinsically connected to the longitudinal context in which it is observed. Recent literature on the subject has seen an increase of studies concerned with the analysis of these 
longitudinal networks in which the time of relationship creation is registered, and network evolution is analyzed $[1,3,16]$. Longitudinal or dynamic networks are similar to cross-sectional or static networks in that they can be onemode (i.e., each link represents a social actor's relationship to another) or two-mode (i.e., each link represents a social actor's affiliation to a group [17], and data involved may be either binary (i.e., the relationship between any two actors is either present or not) or weighted (i.e., the relationship between any two actors presents differing weights) [18].

Generally, two main approaches have been considered to capture longitudinal network dynamics: (i) networklevel and (ii) actor-level [19]. Network-level dynamics have traditionally relied on dependence of likelihood tie formation for which complex simulation methods of structural configurations such as exponential random graph models [20] and stochastic actor-oriented models (henceforth, SAOMs) [21,22] have been developed. These Markovian models define network's future structural behavior as depending from both current and previous state, and explore the evolution of a network based on primary (direct) and secondary (indirect) relationships between actors, as well as on internal or external factors that might affect network change [19,23,24]. Additionally, evolutionary models based on "multi-agent" simulation methods have been developed simulating dynamic network changes over time by modeling the behavior of its actors as computer agents [19]. However, both evolutionary and multi-agent models suffer from few considerable limitations. Specifically, SAOMs infer continuous time processes even though they only observe discrete network snapshots [25]. Additionally, Markovian models present convergence issues when facing complex endogenous (i.e., structural-based) and exogenous (i.e., attribute-based) social changes [19]. Conversely, multiagent models oversimplify complex decision-making of specific actors such as individuals or organizations which can in turn distort real-life network evolution. Most importantly, both Markovian and multiagent models offer a generalist view of network dynamics, often failing to capture individual actor-level involvement in the longitudinal context.

\subsection{A dynamicity approach to longitudinal network analysis}

In the myriad of network evolution studies, little attention has been paid to dynamics of individual importance based on actor-level analysis [4,5,19]. Such "actor-level dynamics" approach captures actor's positional evolution in longitudinal networks by centering itself around two key topologies: (i) static topology which applies traditional social network analysis (henceforth, SNA) methods over an aggregated network encompassing all observational time periods, and (ii) dynamic topology which applies longitudinal analysis techniques over each observational time period referred to as short-interval network. Thus, actor's activity, its structural embeddedness, proximity to other important actors and brokerage position can be captured and analyzed over time. Moreover, this approach can capture the positional change of each actor in longitudinal networks and is useful to determine actor's effect in specific networks such as "disease spread networks" [19] but also in strategic transaction networks where alliances, financing transactions, and merger and acquisition operations (henceforth, M\&A) significantly alter network compositional structure.

Expanding the actor-level approach, Uddin et al. [19] introduce the concept of dynamicity observed by an individual actor as the variability of structural positions of that actor in all short-interval networks compared to its structural position in the aggregated network. This measure is used to quantify actor involvement and contribution in longitudinal communication networks and its behavior against specific perturbations such as organizational crisis. By doing so, the measure takes into account missing data in form of actors' presence and absence which if not counted can severely distort network indicator estimates [26]. In this paper, we take into consideration the latest advances in the study of longitudinal network dynamicity. In this vein, we aim to avoid certain shortcomings inherited by the original dynamicity measures. Specifically, by choosing yearly short-interval networks, as well as global firms as actors for the longitudinal setting, we avoid potential ambiguous behavior observed in Uddin et al. [19] and Hossein et al. (2013) with regard to individual's communication network structure. Additionally, by tracing actor's contribution in the network, we shed light on the dynamic behavior of organizations such as pharmaceutical firms.

\subsection{The structure of actor's network embeddedness}

The actor-level approach has its own followers in social network literature, with most studies researching the structural position of actors and particularly their embeddedness. In general, firm's embeddedness in a network of interorganizational ties has been viewed as a strategic resource, and its important impact on both firms' economic and innovative performance in terms of future capability and expected performance has been rigorously researched [27-33]. However, the extensive use of the term for various conceptualization purposes has somewhat faded its polish in network literature, in part due to scholars' disagreeing conceptual views on embeddedness but also due to the nature of actors involved. Initially, Nahapiet and Goshal [34] dichotomized embeddedness in two conceptual types: (i) structural embeddedness defined as the impersonal configuration of ties between actors which include network measures such as structural holes, connectivity, centrality and hierarchy [35] and (ii) 
relational embeddedness defined as the personal relationships actors have developed due to historical interactions, including measures such as interpersonal trust, trustworthiness and solidarity.

For the purpose of this article, we focus exclusively on structural embeddedness and specifically on key network centrality indicators such as degree, betweenness and closeness, which are widely accepted by social network scholars $[9,32,35]$. While social network literature has showed that centrality measures are only a part of actor's structural embeddedness, researchers believe these indicators are enough to provide a dynamic view of social networks' evolution [8-10]. Centrality, which refers to the network position of an individual actor, denotes the extent to which the focal actor occupies a strategic network position by its involvement in strategically significant ties [36-38]. According to Faust [39] there are several motivators for the existence of network centrality measures. Degree centrality measure is motivated by the fact that actors are central if they are active in the network. Betweenness centrality refers to centrality role of actors if they have the potential to mediate flows of resources or information between other actors, essentially playing a brokerage role [40]. Finally, closeness centrality arises if central actors can contact others through efficient (i.e., short) paths.

\subsection{Strategic transactions as a combined form of interorganizational ties}

Structural embeddedness analysis is a result of actors' tie dynamics which depending on the type of actor (i.e., individual or organizational) can take several forms such as friendship [41,42], communication [19], strategic alliances [43,44], innovation networks [45], knowledge networks [46,47], and research and development partnerships (henceforth, $R \& D$ ) [48] among others. The emergence and formation of ties among organizational actors attributable to both organizational and individual characteristics is at the core of interorganizational networks' formation whose ties are usually created by "boundary spanners" [49]. The rationale behind tie and subsequent network formation can be traced from organizational objectives, management vision for organizational development, and specific strategies necessary to improve firm competitiveness in rapidly changing environments [50]. Given the nature of our data, we focus on networks generated by several interorganizational ties referred to as strategic transactions. We use this term to denominate close interfirm ties that are enduring and of strategic significance for the firms entering them, and include interfirm deals such as strategic alliances, acquisitions and financing collaborations [51]. By analyzing several types of collaborations at once, we contribute to network literature on embedded alliance activity and its impact on structural patterns $[44,52]$, and also enrich literature area devoted to M\&A and financing collaborations [53,54].
Research on strategic transactions varies according to whether the analysis concerns alliance networks or M\&A collaborations. In general, strategic alliance studies have enjoyed continuous popularity in social network literature [43,55-58]. Viewed as access relationships, alliances act as conduits for the flow of hitherto unavailable resources and capabilities [59]. Leading firms, particularly in dynamic industries such as biotechnology, computers and telecommunications, have used strategic alliances (e.g., contractual alliances, consortia, joint ventures) to improve their resource endowment and strategic technological uncertainty towards competitors [60,61]. The key advantages attributable to the establishment of these transaction types include entry in new markets, increased market power, acquisition and exchange of skills, risk and investment sharing, increased institutional legitimacy, accruing network capital and securing firm-level advantages [62]. While these studies have gone to great lengths to describe the nature of strategic alliances, their focus has primarily been on bilateral relationships (i.e., dyadic) often and due to complexity analysis issues, neglecting the role that multilateral alliances play in overall single or multi-industry networks. In fact, firms do engage themselves in alliance groups forming alliance constellations such as codesharing alliances among airlines [6,7], and especially in our case of the global pharmaceutical industry where a wide portfolio of strategic transactions is available, as seen in Table 1.

Conversely, strategic transaction studies based on acquisition or financing networks are considerably fewer $[8,54,63]$. For example, Lin et al. [8] show that networks, learning and institutions represent three building blocks that can enhance our understanding of drivers behind M\&A events. Researchers have supported a view of M\&A network formation based on prior alliances $[8,64]$ which is not our case since we do not necessarily assume acquisitions as a direct result of prior alliance networks. Fabac et al. [54] hypothesize that organizational networks with compatible mixing patterns based on assortativity (i.e., similar actors connected to each-other) will be integrated more successfully while newer network actors will be less attracting components. Conversely, Havila and Salmi [63] consider M\&A as critical events leading to disruption or establishment of actor ties and thus to a radical change in network structure. There has been very little in-depth research on how financing-based transactions contribute to network evolution with Borges and Filion [65] analyzing the spin-off processes that contribute to the development of academic entrepreneurs' social capital. We contribute to this literature by including in our analysis of firm's dynamic embeddedness not only alliance but also financing and acquisition transactions, a reasonable choice from an organizational behavior perspective where strategic transactions are not restricted to specific types. 


\section{TABLE 1}

Strategic Transactions by Type

\begin{tabular}{|c|c|c|}
\hline Alliance & Financing & Acquisition \\
\hline $\begin{array}{l}\text { - Co-marketing } \\
\text { - Co-promotion } \\
\text { - Disease Management } \\
\text { - Includes Contract } \\
\text { - Includes Equity } \\
\text { - Includes Royalty or Profit Split Information } \\
\text { - Intra-Biotech Deal } \\
\text { - Joint Venture } \\
\text { - Manufacturing or Supply } \\
\text { - Marketing-Licensing } \\
\text { - Product or Technology Swap } \\
\text { - Product Purchase } \\
\text { - R + D and Marketing-Licensing } \\
\text { - Reverse Licensing }\end{array}$ & $\begin{array}{l}\text { - Convertible Debt } \\
\text { - FOPO } \\
\text { - Includes Contract } \\
\text { - IPO } \\
\text { - Nonconvertible Debt } \\
\text { - Private Investment in Private Biotech } \\
\text { - Private Placement } \\
\text { - Special-Purpose Financing Vehicle } \\
\text { - Spin-0ff }\end{array}$ & $\begin{array}{l}\text { - Acquisition of Private Biotech } \\
\text { - Buy-out } \\
\text { - Full Acquisition } \\
\text { - Includes Contract } \\
\text { - Includes Earnout } \\
\text { - Intra-Biotech Deal } \\
\text { - Partial Acquisition } \\
\text { - Payment Includes Cash } \\
\text { - Payment Includes Stock } \\
\text { - Reverse acquisition }\end{array}$ \\
\hline
\end{tabular}

Source. Pharma \& MedTech Business Intelligence.

\subsection{Large perturbations' effect on strategic transaction networks}

Inherently embedded in a dynamical setting, strategic transaction networks are continuously affected by perturbations or shocks (i.e., critical events) of both endogenous nature such as organizational crisis $[19,66]$ and exogenous nature such as global financial crises [67-69]. While few studies on endogenous perturbations have analyzed dynamic actor-level patterns [5,70] (Uddin et al. 2011; Hossein et al. 2013), exogenous perturbations' research has focused on understanding complex interactions between engaging actors in a quest to uncover structural pattern formation and evolution [68,71]. Critical events such as organizational crisis are found to have a profound effect on centrality measures such as degree, betweenness and closeness $[5,66,70]$. Specifically, Uddin et al. [5] propose the measure of dynamicity based on centrality indicators to explore underlying endogenous perturbations (i.e., organizational crisis of Enron) to different phases of longitudinal social networks, observing an increase in dynamicity for the crisis period.

Conversely, Minoiu and Reyes [68] find a negative relationship between degree centrality indicators and network perturbations caused by the global financial crisis of 2007-2008, uncovering that structural properties and dynamics of cross-country financial linkages are crucial to understand how the global financial system reacts to shocks, and how systemic risk emerges. On the same lines, Kuzubas et al. [71] show that centrality measures perform well in identifying and monitoring systemically important financial institutions, providing useful insights for financial regulations by showing that after critical events (i.e., Turkish financial crisis), network evolution is considerably less centralized than before. Having said this, evidence on the effects of exogenous shocks on actor-level dynamics as a result of actor's strategic transaction evolution is practically inexistent. Even studies concerning such perturbations $[68,71,72]$ exclude recession effects succeeding these critical scenarios. Our study addresses these shortcomings by not only analyzing the combined effect of the global financial crisis of 2007-2008 and the great recession of 2008-2009, but also by including the impact that more local perturbations such as the Eurozone recession of 2011-2012 have on dynamics of the global pharmaceutical actors and their networking partners. Based on the aforementioned theoretical review which highlights the reduction of centrality measures in the presence of exogenous shocks, we posit our hypotheses for testing as follows:

Hypothesis 1 (H1). The levels of an actor's dynamic embeddedness will be negatively associated to global effects such as the global financial crisis of 2007-2008 and the great recession of 2008-2009.

Hypothesis 2 (H2). The levels of an actor's dynamic embeddedness will be negatively associated to local effects such as the Eurozone recession of 2011-2012.

\section{EMPIRICAL ANALYSIS}

\subsection{Research context}

We choose to conduct our research in the global pharmaceutical industry for several reasons. First, this industry 
is renowned for its contribution to the global economy. Second, strategic transactions such as alliances, financings and acquisitions are the norm in the global pharmaceutical industry. Third, strategic transactions are a meaningful measure of firm's structural embeddedness as confirmed by the literature review in the theoretical framework section. Specifically, strategic alliances which make up 74.5 percent of all strategic transactions in our data have long been considered an optimal source for centrality measures' analysis [73]. Fourth, there is a lack of studies on dynamic embeddedness applied to the global pharmaceutical industry.

\subsection{Data}

We conduct our analysis on a longitudinal dataset ( $T=22$ years, 1991-2012) comprising the strategic transactions of 90 leading firms from the pharmaceutical industry in Western Europe, United States, Asia, Africa and Australia. The sample is selected by identifying those firms that have appeared at least once in the top 50 of the Pharmaceutical Executive Magazine (www.pharmexec.com) yearly editions from the period 2002-2013. Once the sample is defined, we use the Pharma \& Medtech Business Intelligence database (www.pharmamedtechbi.com) to collect all the strategic transactions that involve the firms in question for the available period 1991-2012. We consider transactions starting from 1991 because of the potential contribution of this analysis in determining the global pharmaceutical network structure for an unprecedented period of 22 years, shedding light on the interactions of an industry whose information is difficult to obtain due to the pharmaceutical firm's inherent dynamicity and market's share concentration in few competitors.

The 90 firms of the sample have engaged in alliance, financing and acquisition collaborations with 4645 firms creating a total of 12,055 strategic transactions. It should be noted that due to their nature, the top 90 firms do not engage transactions only in the pharmaceutical industry but have differentiating portfolios which include biotechnology and chemical industries as well. In fact, the total population of firms includes biotech and chemical firms as well as public and private institutions such as research centers and universities. To minimize bias, we decide to include all transactions that firms made with each-other throughout the study period. Additionally, due to data retrieval limitations, we apply the fixed choice effect [74] meaning that strategic transaction constellations are deliberately reduced to 4 participants. However, these applied data limitation techniques represent less than 10 percent of the overall affected strategic transactions; therefore we proceed with the actors' selection using the above design without risking important distortions of network-level statistics as observed by Kossinets [26]. Due to our selection process, we consider two types of firms, the core com-
FIGURE 1

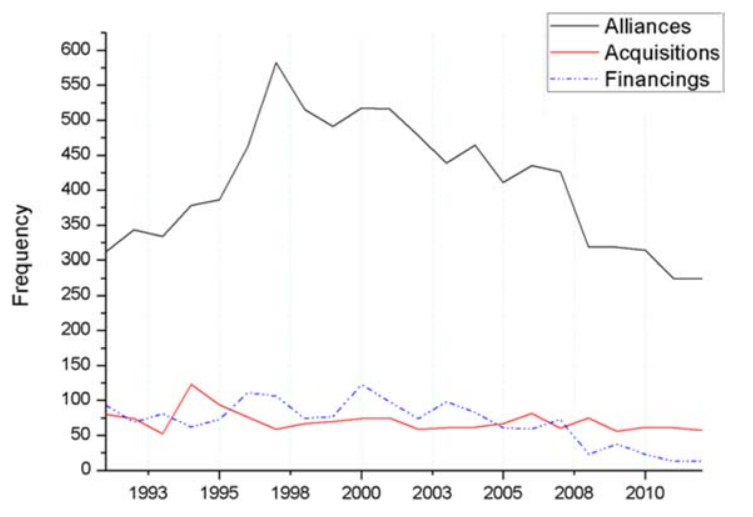

Strategic transactions' evolution 1991-2012.

prised of the top 90 pharmaceuticals and the periphery including the rest of the population, with a total population of 4735 firms whose full list is available from the authors. The obtained longitudinal data for both core and periphery firms, is unbalanced since some firms are acquired by others, or simply are not active for any particular year. This is taken into account when operationalizing the dynamicity variable for each actor, using a constant term whose purpose will be explained in the following paragraphs.

For regression purposes, we obtain financial data using COMPUSTAT (www.compustat.com) and DATASTREAM (www.financial.thomsonreuters.com) databases, supplying missing data using company annual reports. Since financial data concern firms from different countries, we convert all currencies to USD with an exchange rate based on the particular year the data is retrieved. The amount of strategic transactions evolution differs depending on whether the transaction is an alliance, financing or acquisition as seen in Figure 1.

Once our sample is defined, we proceed to build the social networks for both core and periphery firms. We model each year over the sample period as a separate network and analyze the following networks based on a similar approach by Minoiu and Reyes [68]: (i) the core network, referring to the ties between the top 90 actors and (ii) the full network comprising all available data from a total of 4735 actors. To formally characterize such networks, we use the adjacent matrix mathematical concept, meaning a symmetric (i.e., square matrix that is equal to its transpose) $N \times N$ binary adjacent matrix (i.e., sociomatrix) whose generic entry $a_{i j}=a_{j i}=1$ if and only if a link between actor $i$ and $j$ exists and zero otherwise [75]. This means that networks are constructed with binary data, 
i.e., any two actors can either be connected by a tie or not, and the ties between actors are undirected (i.e., reciprocal ties). In accordance with existing literature, we assume the actors shall not have self-referenced ties, meaning the main diagonal of the sociomatrix will always contain zeroes [76].

However many researchers have pointed out that the majority of socio-economic relationships are characterized by a non-reducible heterogeneity. Therefore involving an assessment of how intense (if any) an interaction between two actors is $[75,77]$, binary tie networks run the risk of considering both ties that carry weak and strong flows in a similar manner. Additionally, ties with large weights can potentially have a much larger impact than ties with smaller weights [77]. Therefore, in our analysis, we consider a weighted approach, defined as an $N \times N$ "weight" matrix, whose generic entry $w_{i j}=w_{j i}>0$ measures the interaction intensity between any two actors (zero if no link exists between actor $i$ and $j$ ). This means that ties between actors are valued according to the actual number of strategic transactions, a procedure already seen in the network literature [78]. Additionally, due to data availability issues, the ties considered are of undirected nature. Following this framework and using the software $\mathrm{R}$ that enables us to handle very large vectors, we build 22 symmetric $90 \times 90$ matrices to track the evolution of the core network and 22 symmetric $4735 \times 4735$ matrices to track the evolution of the full network for the period 1991-2012. For dynamicity calculation purposes, we build two aggregate matrices which include the strategic transactions for the entire 22 years period for both core and full networks.

\subsection{Measures}

Prior to the network analysis, we define the indicators used to both track the global pharmaceuticals' evolution and test our hypotheses.

Degree centrality (annotated as $\mathrm{C}_{\mathrm{D}}$ ) formally represents the simplest centrality measure and determines the number of ties for each actor, that is, the number of actors that the focal actor is connected to. However, when analyzing weighted networks, the original measure [36] has been modified to take into account the sum of weights in each tie $[79,80]$ formalized by the following mathematical expression: $C_{D}^{w}(i)=\sum_{j}^{N} w_{i j}$ where $i$ is the focal actor, $j$ represents all other actors, $N$ is the total number of actors, $w$ is the weighted adjacency matrix, in which $w_{i j}$ is greater than 0 if the actor $i$ is connected to actor $j$, and the value represents the weight of the tie. This expression is equal to the definition of degree if the network is binary (i.e., each tie has a weight of 1) [77]. As a consequence, degree centrality scores for any actor will be higher, the more transactions the actor actually has [81].
Betweenness centrality (annotated as $\mathrm{C}_{\mathrm{B}}$ ) formally represents the number of shortest paths between any two actors passing through a specific actor [82]. Therefore, an actor is considered to be well connected if he is located on as many of the shortest paths between pairs of other actors [81]. However, in weighted networks, the actors with the highest actor strength are more likely to be connected in networks from a range of different domains [80]. This means that the shortest (i.e., geodesic) path to reach an actor would be the path that has more weight, that is, the likelihood of an actor acting as a broker in a network would increase if it has stronger ties with other actors. The mathematical expression for this measure is: $C_{B}^{w}(i)=$ $\frac{g_{i j}^{w}(i)}{g_{i j}^{w}}$ where $g_{i j}^{w}$ is the number of the weighted shortest paths between actors $\mathrm{i}$ and $\mathrm{j}(i \neq j)$ and $g_{i j}^{w}(i)$ is the number of those paths that go through actor $i$.

Closeness centrality (annotated as $\mathrm{C}_{\mathrm{C}}$ ) formally represents the inverse total length of the paths from an actor to all other actors in the network. This measure is based on the idea that actors with a short distance (i.e., path) to others can spread information very productively through the network [81]. Therefore, closeness centrality values increase when the geodesic distance between any two actors decreases. The mathematical expression for this measure is: $C_{C}^{w}=\left[\sum_{j=1}^{N} d^{w}(i, j)\right]^{-1}$ where $d^{w}(i, j)=\min$ $\left(\frac{1}{w_{i h}}+\ldots+\frac{1}{w_{h j}}\right) ; d^{w}(i, j)$ is the shortest path between actors $i$ and $j$, and $h$ are intermediary actors on paths between $i$ and $j$ as observed by Opsahl et al. [77]. All weighted centrality measures in our analysis have been normalized and are calculated using 'tnet' package available in R software.

Dynamicity represents the variability of structural positions of an actor in all short-interval networks compared to its structural position in the aggregated network. The mathematical expression for this measure originally proposed by Uddin et al. [5] is given in the following equation (1):

$$
\frac{D D A^{i}=\sum_{t}^{m} \alpha_{t, t-1} \times\left|O V_{A N}-O V_{t}\right|}{m}
$$

where $D D A^{i}$ is the degree of dynamicity shown by $i$ th actor, $O V_{A N}$ is the observed value (i.e., degree centrality) for the aggregated network, $O V_{t}$ is the observed value (i.e., degree) fort $t$ th yearly network for the $i$ th actor, $m$ is the number of yearly networks considered in the analysis, and $\alpha_{t, t-1}$ is a constant valued according to whether the actor is present or missing in the current and previous shortinterval network. The presence of this constant is of crucial importance to properly count for actors that disappear from the network due to simple inactivity or possible lack of presence due to acquisition effects. The possible combination of values that $\alpha_{t, t-1}$ takes are the following: (i) 1 if the actor is present in both current and previous period (t), (ii) 0.5 if the actor is present in current period but absent in the previous one, and (iii) 0 if the actor is absent 
from the current period irrespective of his presence in the previous period.

For the first short-interval (yearly) network (i.e., $\alpha_{i, 0}$ for $t=0$ ), the value of the constant will depend on the presence or absence of each actor (i.e., either 1 or 0 ) at that particular period which further differentiates our model from the original one. It should be noted that degree, betweenness and closeness measures are introduced in their absolute form to both Eqs. (1) and (2). The dynamicity model [5] differentiates between two types of dynamicity measures, the dynamicity of an actor represented by Eq. (1) and the average dynamicity shown by an actor of the $t$ th short-interval network represented by Eq. (2):

$$
\frac{D D N^{t}=\sum_{t}^{w_{t}} \alpha_{t, t-1} \times\left|O V_{A N}^{j}-O V_{t}\right|}{w_{t}}
$$

where $D D N^{t}$ is the average degree of dynamicity shown by an actor of the $t$ th short-interval network, and $w_{t}$ is the total number of actors in the $t$ th yearly network. Therefore, our analytical approach is based on three variables: degree dynamicity, betweenness dynamicity and closeness dynamicity constructed by substituting each centrality measure to Eqs. (1) and (2).

To analyze the effect of exogenous critical events such as financial crises and recessions on the global pharmaceutical industry, we construct two main effect variables: global crisis represents the combined effect of the global financial crisis of 2007-2008 and the great recession of 2008-2009 that followed as a direct consequence. To avoid potentially high correlations between the crisis and the recession, as well as knowing that the great recession was originally a direct consequence of the financial crisis, we decide to combine both these critical events into one dummy variable that takes the value of 1 for the years 2007-2009 and zero for the rest. Local crisis represents the exogenous effect of the Eurozone recession during 2011-2012. Even though the recession continued well into 2013, due to lack of data, we consider only the effect for the period 2011-2012. Specifically, we create a dummy variable that takes the value of 1 for the years 2011-2012 and zero for the rest. Additionally, we do not include 2010 in our analysis as it has been deemed a "recovery" period.

In multivariate analyses, we use various actor-specific measures including several financial controls, a wellknown procedure accounting for the possibility that differentiates between firms in terms of how financial performance affects their propensity to engage in strategic transactions [44]. The control indicators include strategic transaction frequency, R\&D intensity, profitability, headquarters (HQ) location and financial leverage. Strategic transaction frequency represents the relative frequency in percentage with which firms engage in strategic transactions. Knowing that about $75 \%$ of strategic transactions present in the data are alliances, with the rest split evenly close (about $12.5 \%$ ) between financing and acquisition collaborations, it is deemed important to control for the effect of each transaction type on actor's dynamicity. $R \& D$ intensity represents the firm's $R \& D$ expenditure scaled by total sales, as seen in network literature $[83,84]$. We measure profitability for each firm by computing the ratio of net income to total assets (ROA), an indicator that has been well-accepted as a proxy of firm's performance [84]. Another important financial measure is financial leverage (i.e., debt-to-total assets including both short- and longterm debt) [85]. While the use of this measure as such is subject to scrutiny [86], we believe its use as a control variable for this type of network-based study is feasible. Additionally, based on the existing network literature $[84,87]$, we control for the age of the firms, operationalized as the foundation year minus the year considered in the 2002-2012 longitudinal analysis and size, operationalized as the natural logarithm of company's employees. Since our data consists of global firms and knowing that the majority of top pharmaceutical firms are either US- or EU-based, we control for headquarters (HQ) location based on two separate dummy variables representing whether firms are U.S. or EU firms.

We use the dynamicity-based centrality measures for two purposes: (i) to analyze network evolution from the perspective of actors' dynamic embeddedness for the period 1991-2012 applied to both network types, and (ii) to test our hypotheses using a specific panel (i.e., longitudinal) regression model for the period 2002-2012 (i.e., \pm 5 years from the offset of the global financial crisis) for the core network and a mean comparison ANOVA test for the full network. An important question regarding actors' dynamicity is how to determine the stability of dynamic embeddedness distribution throughout the study period. To achieve this, we use a two-step analysis process similar to Minoiu and Reyes [68]; first we compare Kernel Density Estimates (henceforth, KDE) for core network dynamicity in the beginning and the end of our sample period, second we assess these distributions using Kolmogorov-Smirnov (henceforth, KS) tests for both core and full network. By controlling for firm-specific effects, we investigate the effect that global crisis (including the global financial crisis of 2007-2008 and the great recession of 2008-2009), and the local crisis referring to the Eurozone recession observed for 2011 and 2012, have on degree, betweenness and closeness dynamicity.

To test our hypotheses, we choose an econometric model conditioned by several factors. First, as the panel exhibits first-order serial correlation, we use GLS estimators for random effects with the disturbance term modeled as an AR (1) process. Second, since we consider a short panel of ten years, fixed-effects models are biased over short periods, thus RE models are preferred [88]. 


\section{TABLE 2}

Descriptive Statistics of Variables Used in Regression Models

\begin{tabular}{|c|c|c|c|c|c|c|}
\hline Variables & & $N$ & Mean & SD & Min & $\operatorname{Max}$ \\
\hline \multicolumn{7}{|c|}{ A. Dependent variables } \\
\hline & Degree dynamicity & 753 & 0.13 & 0.17 & 0.00 & 1.02 \\
\hline & Betweenness dynamicity & 753 & 0.07 & 0.12 & 0.00 & 0.81 \\
\hline & Closeness dynamicity & 753 & 0.02 & 0.02 & 0.00 & 0.08 \\
\hline \multicolumn{7}{|c|}{ B. Network characteristics } \\
\hline \multicolumn{7}{|c|}{ Strategic transaction frequency } \\
\hline & Alliance & 752 & 0.71 & 0.31 & 0.00 & 1.00 \\
\hline & Financing & 752 & 0.06 & 0.13 & 0.00 & 1.00 \\
\hline & Acquisition & 752 & 0.12 & 0.18 & 0.00 & 1.00 \\
\hline \multicolumn{7}{|c|}{ C. Industry characteristics } \\
\hline Global crisis & & 753 & 0.27 & 0.44 & 0.00 & 1.00 \\
\hline Local crisis & & 753 & 0.15 & 0.36 & 0.00 & 1.00 \\
\hline \multicolumn{7}{|c|}{ D. Firm characteristics } \\
\hline Age & & 753 & 74.98 & 66.13 & 0.00 & 344.00 \\
\hline Size & & 752 & 9.30 & 1.76 & 0.00 & 12.04 \\
\hline \multicolumn{7}{|l|}{ HQ Location } \\
\hline & U.S. firms & 753 & 0.38 & 0.49 & 0.00 & 1.00 \\
\hline & EU firms & 753 & 0.39 & 0.49 & 0.00 & 1.00 \\
\hline R\&D intensity & & 753 & 1.42 & 34.90 & 0.00 & 957.72 \\
\hline Profitability & & 753 & 0.07 & 0.09 & -0.84 & 0.61 \\
\hline Financial leverage & & 753 & 0.20 & 0.18 & 0.00 & 1.20 \\
\hline
\end{tabular}

Third, the RE model is preferred after a Hausman test indicates consistency and efficiency for our choice. Fourth, we run a Breusch-Pagan Lagrange multiplier test to determine whether a pooled OLS regression would have been more appropriate which gives a significant result rejecting the null hypothesis, therefore preferring the $\mathrm{RE}$ model [89]. Additionally, we control for multicollinearity by computing Variance Inflation Factors (henceforth, VIF) on all explanatory variables. VIF are well below the 2.5 threshold considered for weaker models. Since the financial information considered for regression analysis presents missing data throughout the years, our regression models use unbalanced data. To explore the effects of the global and local crises on the full network, we conduct several one way Analysis of Variance (ANOVA) tests, similarly to the methodology shown by Fogel and Nehmad [90] in order to compare the dynamic embeddedness for the years prior and post to the financial crisis offset. Specifically, we compare the mean between the periods before the financial crisis (2004-2006), the global crisis period (2007-2009) and the local Eurozone crisis included in the period (2010-2012). Table 2 shows a detailed description of the above-mentioned variables.

\section{RESULTS}

We describe the dynamics of the global pharmaceutical industry using four key estimates: (i) tracking dynamic embeddedness evolution based on average dynamicity estimate plots, (ii) monitoring the stability variation of actors' dynamic embeddedness based on KDE and KStests, (iii) constructing the top ten firm rankings based on yearly network average dynamicity estimates, and (iv) understanding the global and local crises association effect on dynamic embeddedness based on computational visualizations and panel regression estimates. Results (i)-(iii) concern the total panel period 1991-2012 while results (iv) concern the panel period 2002-2012.

\subsection{Dynamic Embeddedness Evolution}

Table 3 provides summary statistics for selected dynamicity measures including start and end years of our sample. Looking at both networks, we observe dynamicity means of all centrality indicators increase in 1998 compared to 1991, but decrease in both 2008 and 2012 with the latter showing a marked drop compared to previous years. Additionally, actors' dynamic embeddedness in 2012 reaches values never seen since the beginning of the sampling period. For some measures, this change is most visible for the period 2007-2012, suggesting some critical event impacting the values. This effect is more visible in the full network compared to the core one, suggesting a more stable relationship between actors within the top 90 network. Furthermore, the standard deviation values are comparable to the mean, suggesting a high degree of variation in the dynamicity across centrality measures. This 


\section{TABIE 3}

Summary Statistics for Selected Years

\begin{tabular}{|c|c|c|c|c|c|c|}
\hline & \multicolumn{3}{|c|}{ Panel A: core network } & \multicolumn{3}{|c|}{ Panel B: full network } \\
\hline & Degree & Betweenness & Closeness & Degree & Betweenness & Closeness \\
\hline \multicolumn{7}{|l|}{1991} \\
\hline Mean & $1.14 \mathrm{E}-03$ & $4.75 \mathrm{E}-04$ & $1.88 \mathrm{E}-07$ & $5.13 \mathrm{E}-07$ & $8.15 \mathrm{E}-08$ & $1.81 \mathrm{E}-12$ \\
\hline Median & $5.87 \mathrm{E}-04$ & 0.00 & $1.23 \mathrm{E}-07$ & 0.00 & 0.00 & 0.00 \\
\hline S.D. & $1.60 \mathrm{E}-03$ & $1.04 \mathrm{E}-03$ & $2.01 \mathrm{E}-07$ & $4.08 \mathrm{E}-06$ & $9.22 \mathrm{E}-07$ & $5.13 \mathrm{E}-12$ \\
\hline Min. & 0.00 & 0.00 & 0.00 & 0.00 & 0.00 & 0.00 \\
\hline Max. & $9.69 \mathrm{E}-03$ & $5.99 \mathrm{E}-03$ & $1.71 \mathrm{E}-07$ & $1.08 \mathrm{E}-04$ & $2.96 \mathrm{E}-05$ & 2.74 E-11 \\
\hline \multicolumn{7}{|l|}{1998} \\
\hline Mean & 1.16 E-03 & $6.17 \mathrm{E}-04$ & $2.84 \mathrm{E}-07$ & 5.64 E-07 & $2.03 \mathrm{E}-07$ & $1.41 \mathrm{E}-12$ \\
\hline Median & $6.18 \mathrm{E}-04$ & $1.03 \mathrm{E}-04$ & $3.08 \mathrm{E}-07$ & 0.00 & 0.00 & 0.00 \\
\hline S.D. & $1.54 \mathrm{E}-03$ & $1.13 \mathrm{E}-03$ & $2.02 \mathrm{E}-07$ & $4.02 \mathrm{E}-06$ & $2.94 \mathrm{E}-06$ & $3.67 \mathrm{E}-12$ \\
\hline Min. & 0.00 & 0.00 & 0.00 & 0.00 & 0.00 & 0.00 \\
\hline Max. & 9.55 E-03 & 5.67 E-03 & $6.23 \mathrm{E}-07$ & $1.06 \mathrm{E}-04$ & $1.13 \mathrm{E}-04$ & $2.11 \mathrm{E}-11$ \\
\hline \multicolumn{7}{|l|}{2007} \\
\hline Mean & $1.02 \mathrm{E}-03$ & $5.11 \mathrm{E}-04$ & $1.53 \mathrm{E}-07$ & $4.90 \mathrm{E}-07$ & $2.73 \mathrm{E}-07$ & $9.90 \mathrm{E}-13$ \\
\hline Median & $2.43 \mathrm{E}-04$ & 0.00 & 8.34 E-08 & 0.00 & 0.00 & 0.00 \\
\hline S.D. & $1.65 \mathrm{E}-03$ & $1.08 \mathrm{E}-03$ & $1.85 \mathrm{E}-07$ & $4.08 \mathrm{E}-06$ & $3.51 \mathrm{E}-06$ & $2.72 \mathrm{E}-12$ \\
\hline Min. & 0.00 & 0.00 & 0.00 & 0.00 & 0.00 & 0.00 \\
\hline Max. & 9.91 E-03 & 5.07 E-03 & 7.03 E-07 & $1.10 \mathrm{E}-04$ & 1.09 E-04 & $1.57 \mathrm{E}-11$ \\
\hline \multicolumn{7}{|l|}{2012} \\
\hline Mean & 7.24 E-04 & 4.30 E-04 & 1.07 E-07 & 3.79 E-07 & 9.66 E-08 & $9.09 \mathrm{E}-13$ \\
\hline Median & 0.00 & 0.00 & 0.00 & 0.00 & 0.00 & 0.00 \\
\hline S.D. & $1.63 \mathrm{E}-03$ & $1.28 \mathrm{E}-03$ & $1.71 \mathrm{E}-07$ & $3.98 \mathrm{E}-06$ & $1.42 \mathrm{E}-06$ & $3.46 \mathrm{E}-12$ \\
\hline Min. & 0.00 & 0.00 & 0.00 & 0.00 & 0.00 & 0.00 \\
\hline Max. & 1.02 E-02 & 5.54 E-03 & 7.46 E-07 & $1.13 \mathrm{E}-04$ & 3.85 E-05 & $2.73 \mathrm{E}-11$ \\
\hline
\end{tabular}

result, coupled with the observed difference between mean and median, provides further proof to the variability and skewness of actors' dynamic embeddedness.

Figure 2 plots the cross-sectional averages of dynamic indicators during 1991-2012. For visualization simplicity, all values related to dynamic embeddedness (i.e., degree, betweenness, closeness) have been rescaled using an appropriate constant for both plotting and regression purposes. Results show that dynamicity values are stabile for degree centrality, but vary substantially for betweenness and

\section{FIGURE 2}
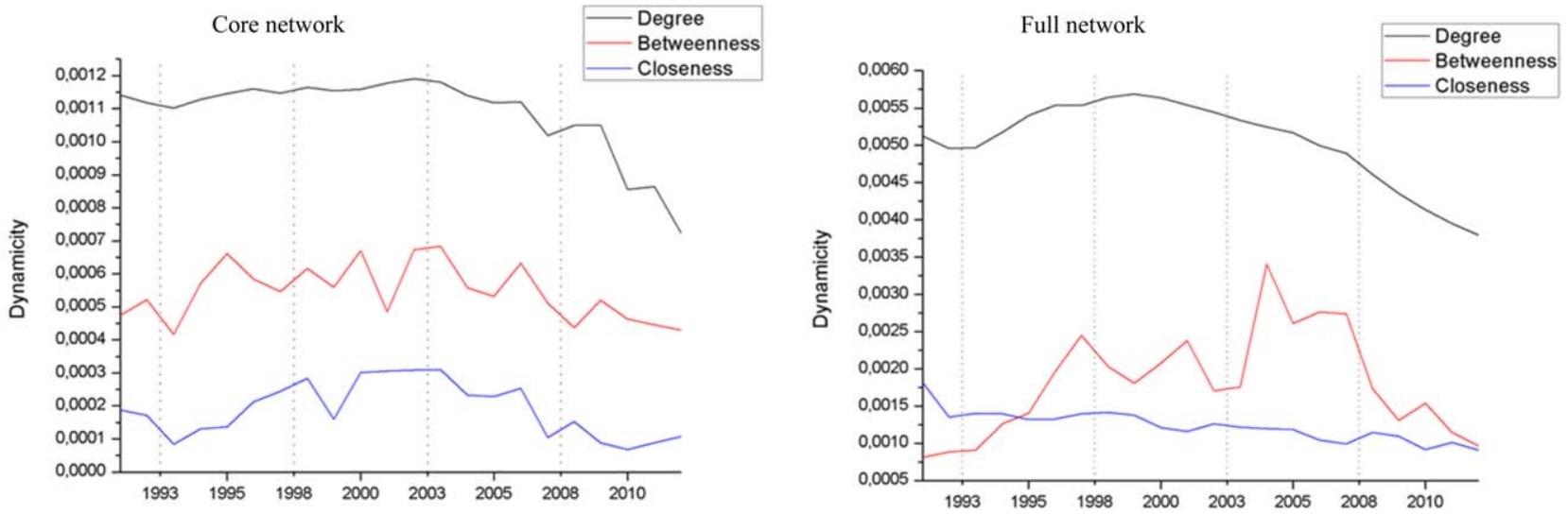

Dynamic embeddedness evolution 1991-2012 for both core and full networks. 


\section{FIGURE 3}
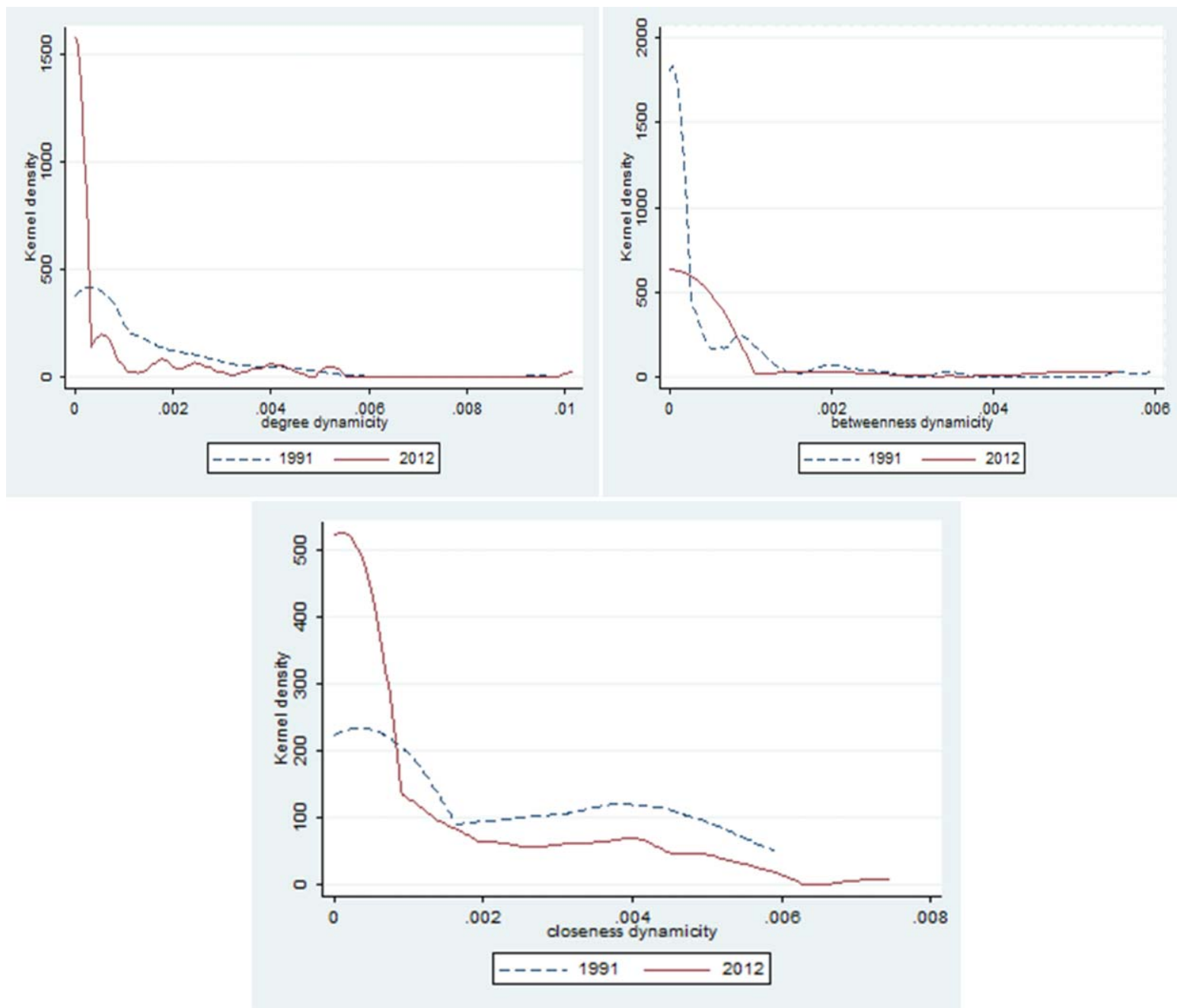

Dynamic embeddedness distribution for core networks.

closeness centrality. Particularly of interest is the values' behavior during the offset of the global financial crisis of 2007-2008, with the estimates plummeting for both types of network. Specifically, for the core network, degree and betweenness dynamicity drop respectively $20 \%$ and $17 \%$ while closeness dynamicity is almost halved by $40 \%$ during the global crisis. The more local Eurozone crisis of 2011-2012 shows a similar trend with both networks' dynamicity severely reduced. An exception is closeness centrality, whose dynamicity shows an upward trend for the core network, with signs of a more clustering-oriented tendency.

\subsection{Dynamic Embeddedness Stability}

We assess actors' dynamic embeddedness stability by analyzing dynamicity distribution via KDE comparisons.
Specifically, we plot the nonparametric density estimates for centrality-based dynamicity including the sample's start and end year for the core network. As seen from Figure 3, dynamicity has a similar shape for all three centrality measures; however degree and closeness dynamicity have shifted downwards showing a clear tendency for the firms to reduce connections and proximity to each-other while betweenness dynamicity plotting the brokerage tendency of the firms shows signs of alternation with both left and rightward movements.

To understand whether this tendency is a mere isolated event or a result of dynamic network evolution, we test the stability of core network dynamicity distributions and compare it with the full network. For this, we compare each dynamicity distribution in the first year of each 


\section{TABLE 4}

Empirical Distribution Stability for Dynamic Embeddedness

\begin{tabular}{|c|c|c|c|c|c|c|c|}
\hline Panel A: Core network & 1991 & 2001 & 2012 & Panel B: Full network & 1991 & 2001 & 2012 \\
\hline Degree & & & & Degree & & & \\
\hline $1991-2001$ & & & 1.00 & $1991-2001$ & 0.54 & 0.27 & 1.00 \\
\hline 2002-2012 & 0.36 & 0.27 & 0.72 & 2002-2012 & 0.54 & 0.45 & 0.63 \\
\hline Betweenness & & & & Betweenness & & & \\
\hline 1991-2001 & & & 1.00 & $1991-2001$ & & & 0.18 \\
\hline $2002-2012$ & 0.27 & 0.36 & 0.54 & $2002-2012$ & & 0.18 & \\
\hline Closeness & & & & Closeness & & & \\
\hline $1991-2001$ & 0.54 & 0.72 & 0.90 & $1991-2001$ & 1.00 & 0.81 & 1.00 \\
\hline $2002-2012$ & 0.63 & 0.63 & 0.45 & $2002-2012$ & 1.00 & 0.72 & 0.63 \\
\hline
\end{tabular}

Note. Only significant coefficients reported for * $p<.05$.

decade as well as last year's available (1991, 2001, and 2012) with subsequent years in the same decade, a procedure seen in Minoiu and Reyes [68] and which results are given in Table 4 .

We show the proportion of years when dynamicity distribution is statistically different (at 5 percent level of significance) in each decade compared to 1991, 2001, and 2012. Not reported values mean that the distribution of a particular year compared to a particular decade is statistically close, such as the case for degree and betweenness dynamicity for years 1991 and 2001 compared with the period 1991-2001. This means that in both core and full networks firms have kept a similar centrality structure. On the other hand, the distribution for the decade 2002-2012 is statistically different for almost all dynamicity variables in both core and full networks, meaning that actors' dynamicity has been highly unstable for the second decade. An exception concerns betweenness dynamicity for the full network, whose results show a relatively unaffected actors' brokerage tendency, with only 18 percent of significant distribution change. Interestingly, closeness dynamicity exhibits the most significant change in both networks with overall distributions' difference higher in the full network.

\subsection{Firm Rankings in the Global Pharmaceutical Industry}

One of the key contributions of the dynamicity measure is its ability to provide a ranking based on actor's network measures' evolution. This is crucial in understanding the contribution of each actor to network dynamics. Knowing the high market share that few pharmaceutical firms have in the global industry, we focus on the top ten dynamicity ranking, and report the first ten pharmaceutical firms that have the highest score for centrality measures of both network types as seen in Table 5 .
We observe that the top ten ranking for both degree and betweenness dynamicity includes seven of the biggest pharmaceutical firms (based on their average total sales) which are highlighted in bold, meaning these firms score high in their centrality position during core network evolution. Interestingly, closeness dynamicity shows only three big pharmaceuticals in the top ten, with a clear tendency of smaller firms reducing their mutual proximities. However, big pharmaceutical firms' hegemony is reinstated in the full network where we observe nine big pharmaceuticals scoring high in their degree and betweenness dynamicity measures and eight big pharmaceuticals scoring high in closeness centrality.

\subsection{The Global and Local Crisis Effect on Dynamicity}

The dynamicity distribution results shown in the KS test give us a statistically important clue that during the 2002-2012 decade some major perturbation event occurred. To understand the network instability of the second decade, we focus our attention on the global crisis with its offset in December 2007 and the more local Eurozone crisis starting in 2011. Following this line of thought, we proceed by visualizing the strategic transactions between actors for core networks during the global financial crisis offset in 2007 and the Eurozone recession in 2012 as seen in Figure 4 using R software.

As observed, the overall strategic transactions between core network members have seen a marked reduction when comparing the global financial crisis offset in 2007 with 2012, the last year in our analysis. In addition to the reduced transactions, the number of isolates (i.e., firms without ties) represented as dots encircling the connections, has increased though this is often the case due to firms not making it to the top 50 list or being acquired by others. Prior to showing the regression analysis estimates, 


\section{TABLE 5}

Top-10 Firms Ranking (1991-2012) in Core and Full Networks According to Dynamic Embeddedness

\begin{tabular}{|c|c|c|c|c|c|c|c|c|}
\hline \multicolumn{3}{|c|}{ Degree } & \multicolumn{3}{|c|}{ Betweenness } & \multicolumn{3}{|c|}{ Closeness } \\
\hline Rank & Name & Value & Rank & Name & Value & Rank & Name & Value \\
\hline \multicolumn{9}{|c|}{ Core network } \\
\hline 1 & Pfizer & 0.879 & 1 & Novartis & 0.407 & 1 & GlaxoSmithKline & $4.68 \mathrm{E}-05$ \\
\hline 2 & Roche & 0.460 & 2 & Daiichi Sankyo & 0.381 & 2 & Baxter International & $4.66 \mathrm{E}-05$ \\
\hline 3 & Sanofi & 0.455 & 3 & Sanofi & 0.369 & 3 & AstraZeneca & $4.42 \mathrm{E}-05$ \\
\hline 4 & Novartis & 0.385 & 4 & GlaxoSmithKline & 0.344 & 4 & Medlmmune & $4.31 \mathrm{E}-05$ \\
\hline 5 & Merck & 0.366 & 5 & Pfizer & 0.232 & 5 & Tanabe Seiyaku & $4.15 \mathrm{E}-05$ \\
\hline 6 & Teva & 0.358 & 6 & Roche & 0.202 & 6 & Ratiopharm & $4.14 \mathrm{E}-05$ \\
\hline 7 & AstraZeneca & 0.356 & 7 & Teva & 0.189 & 7 & Johnson and Johnson & $4.08 \mathrm{E}-05$ \\
\hline 8 & GlaxoSmithKline & 0.334 & 8 & Abbott Laboratories & 0.165 & 8 & Allergan & $4.02 \mathrm{E}-05$ \\
\hline 9 & Genzyme & 0.306 & 9 & AstraZeneca & 0.160 & 9 & Genzyme & $3.89 \mathrm{E}-05$ \\
\hline 10 & Genentech & 0.257 & 10 & Merck & 0.153 & 10 & Daiichi & $3.78 \mathrm{E}-05$ \\
\hline \multicolumn{9}{|c|}{ Full network } \\
\hline 1 & Pfizer & 0.516 & 1 & GlaxoSmithKline & 0.269 & 1 & Pfizer & $9.40 \mathrm{E}-08$ \\
\hline 2 & GlaxoSmithKline & 0.384 & 2 & Pfizer & 0.231 & 2 & GlaxoSmithKline & $9.04 \mathrm{E}-08$ \\
\hline 3 & Johnson and Johnson & 0.360 & 3 & Johnson and Johnson & 0.182 & 3 & Roche & $8.54 \mathrm{E}-08$ \\
\hline 4 & Sanofi & 0.326 & 4 & Novartis & 0.181 & 4 & Sanofi & 8.52 E-08 \\
\hline 5 & Roche & 0.311 & 5 & Roche & 0.180 & 5 & Novartis & $8.20 \mathrm{E}-08$ \\
\hline 6 & Novartis & 0.298 & 6 & Bristol-Myers Squibb & 0.178 & 6 & Bristol-Myers Squibb & $8.11 \mathrm{E}-08$ \\
\hline 7 & Bayer AG & 0.277 & 7 & Merck & 0.166 & 7 & Genzyme & $8.10 \mathrm{E}-08$ \\
\hline 8 & Bristol-Myers Squibb & 0.254 & 8 & Sanofi & 0.161 & 8 & Genentech & $8.08 \mathrm{E}-08$ \\
\hline 9 & Merck & 0.250 & 9 & Abbott Laboratories & 0.154 & 9 & Johnson and Johnson & $7.87 \mathrm{E}-08$ \\
\hline 10 & Bayer Corp. & 0.246 & 10 & Aventis & 0.118 & 10 & AstraZeneca & $7.85 \mathrm{E}-08$ \\
\hline
\end{tabular}

Note. Firms in bold are present in the top ranking according to sales.

we provide the correlation matrix of all variables used in regression models as seen in Table 6 .

The correlation coefficients show high and significant values for certain variables such as degree dynamicity, betweenness dynamicity and firm size. Overall, the dependent dynamicity variables are positively and significantly correlated to each-other, with the explanatory variables having relatively low correlation coefficients. This tendency points to no multicollinearity problems as acknowledged by the VIF analysis mentioned in the previous section. The analyses performed so far seem to support our hypotheses of a negative effect of global and local crisis on actor's dynamic embeddedness. To further explore their accuracy, we perform a multivariate analysis, meaning a panel regression analysis with random-effects using the core network of 90 firms as our sample. Table 7 summarizes the results.

Looking at the main effects, our hypotheses are confirmed by the regression results. Specifically, we find strong support for hypothesis 1 regarding the negative effect of the global crisis on dynamicity indicators except degree dynamicity (model 1), meaning that the combined effect of the global financial crisis 2007-2008 and the subsequent great recession of 2008-2009 have significantly affected betweenness and closeness dynamicity of the core network members. Moreover, we find strong statistical significance in all three models for the negative effect that local Eurozone crisis has had on firms' dynamic embeddedness in support of hypothesis 2. Interestingly enough, each model presents its own significant

\section{FIGURE 4}

Core network in 2007
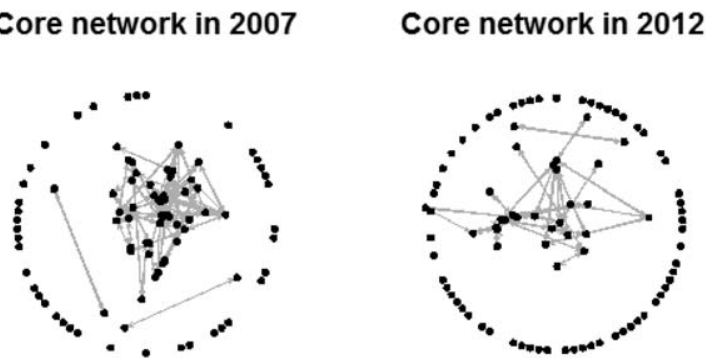

Core network activity during global financial crisis offset and ongoing Eurozone recession. 


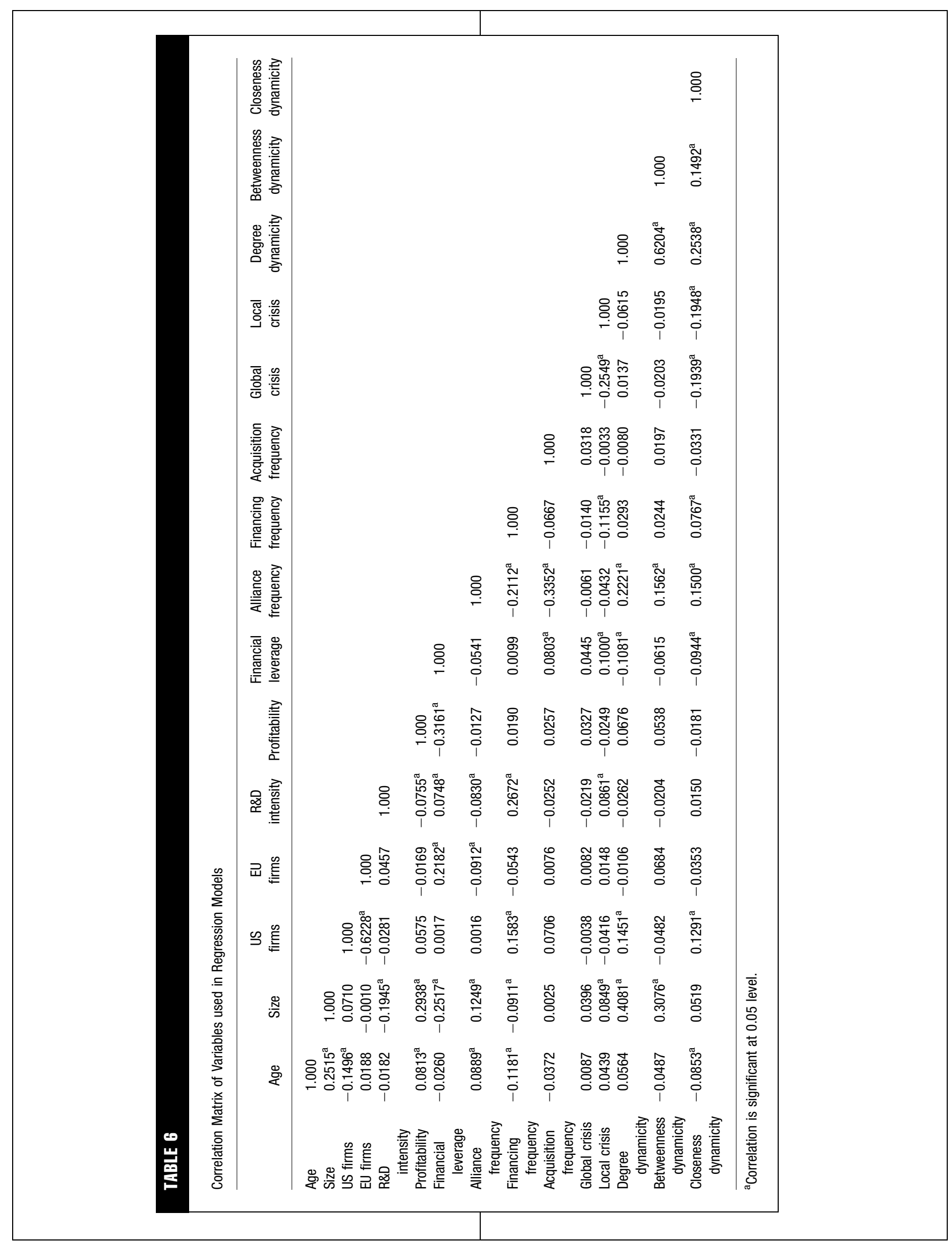




\section{TABLE 7}

Dynamic Embeddedness During Crises: RE GLS Regression with AR (1) Disturbance Estimates

\begin{tabular}{|c|c|c|c|}
\hline \multirow[b]{2}{*}{ Variables } & \multicolumn{3}{|c|}{ Dynamic embeddedness } \\
\hline & $\begin{array}{l}\text { Model } 1 \\
\text { Degree }\end{array}$ & $\begin{array}{c}\text { Model } 2 \\
\text { Betweenness }\end{array}$ & $\begin{array}{c}\text { Model } 3 \\
\text { Closeness }\end{array}$ \\
\hline \multicolumn{4}{|l|}{ Controls } \\
\hline Age & -0.000129 & $-0.000321^{*}$ & -0.0000312 \\
\hline Size & $0.00817^{\star}$ & $0.0184^{\star \star \star}$ & -0.000196 \\
\hline \multicolumn{4}{|l|}{ HQ location } \\
\hline US firms & $0.0820^{*}$ & -0.0227 & $0.00978^{\star}$ \\
\hline EU firms & 0.0429 & 0.00302 & 0.00648 \\
\hline R\&D intensity & -0.0000596 & 0.0000133 & 0.00000101 \\
\hline Profitability & -0.0048 & 0.0371 & $-0.0180^{\star}$ \\
\hline Financial leverage & -0.0062 & 0.0321 & $-0.0181^{\star \star \star}$ \\
\hline \multicolumn{4}{|c|}{ Strategic transaction frequency } \\
\hline Alliance & $0.0194^{\star \star \star}$ & 0.0151 & $0.00634^{\star \star}$ \\
\hline Financing & 0.0116 & 0.00373 & 0.00398 \\
\hline Acquisition & $0.0220^{\star \star}$ & 0.0154 & 0.00392 \\
\hline \multicolumn{4}{|l|}{ Main effects } \\
\hline Global crisis & 0.00273 & $-0.0143^{\dagger}$ & $-0.00512^{\star \star \star}$ \\
\hline Local crisis & $-0.0184^{\star \star \star}$ & $-0.0210^{\star}$ & $-0.00731^{\star \star \star}$ \\
\hline \multicolumn{4}{|l|}{ Model statistics } \\
\hline Constant & -0.00242 & $-0.0916^{\dagger}$ & $0.0189^{\star}$ \\
\hline$R^{2}$ overall & 0.1088 & 0.1272 & 0.1071 \\
\hline$N$ & 751 & 751 & 751 \\
\hline
\end{tabular}

Note. Standardized coefficients are reported ${ }^{\dagger} p<0.1,{ }^{\star} p<0.05$, ${ }^{\star \star} p<0.01,{ }^{\star * \star} p<0.001$.

peculiarities for example, firms' size impacts degree and betweenness but not closeness dynamicity, meaning that larger firms have an increased probability of engaging in strategic transactions as well as functioning as intermediaries between each two other firms. From financial measures' viewpoint, we observe that closeness dynamicity is significantly reduced by profitability and financial leverage. Additionally, strategic transaction types have an influence on dynamic embeddedness. While this result in the case of alliance transactions can be attributed to the relatively high distribution of this transaction type in the sample (about $75 \%$ ), the positive and significant effect of acquisition transactions on degree dynamicity is rather interesting considering that both acquisition and financing transactions show similar distributions in the sample (about $12.5 \%$ each). Table 8 shows the one way ANOVA test results, in an attempt to understand the mean distribution of dynamic embeddedness in the full network population for the years prior and after the financial crisis triggering both the global and Eurozone recessions.

According to the ANOVA tests, the distribution mean for factor 1 representing period 2004-2006, factor 2

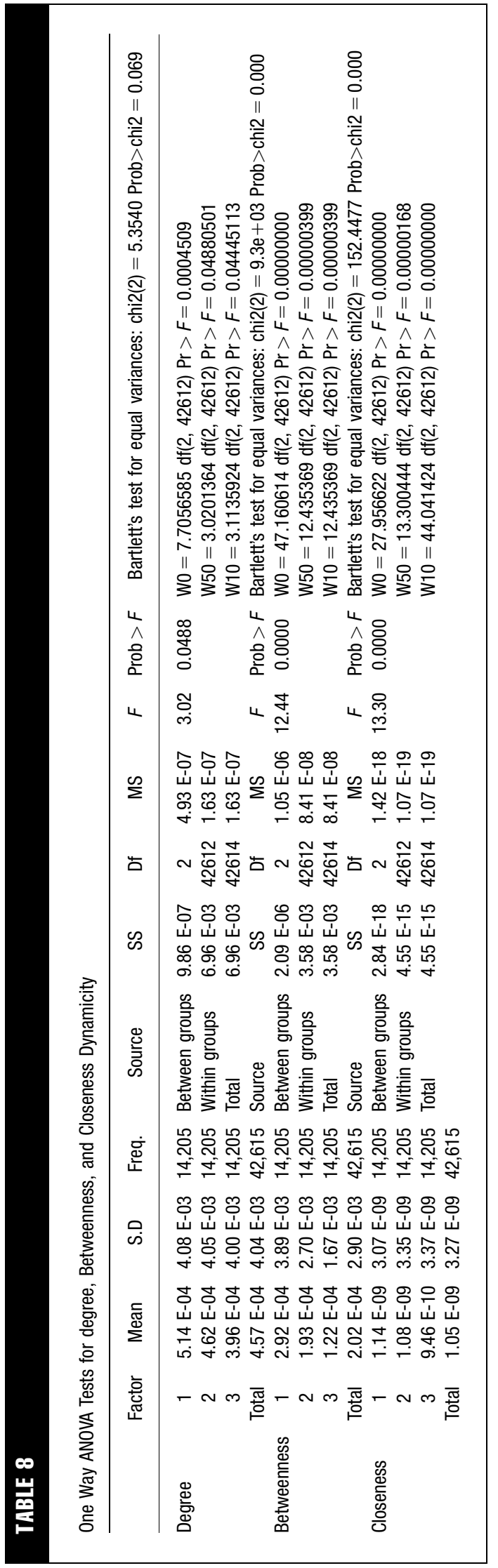


representing period 2007-2009 and factor 3 representing period 2010-2012 significantly differ from each-other (i.e., $p<0.05)$ for the three dynamicity indicators. Therefore, also for full networks, degree, betweenness and closeness indicators show a decreasing tendency across the ANOVA factors supporting the negative and significant effect of the crisis and subsequent recessions on firm-level degree of dynamicity. However, the low $p$ value based on Bartlett's test cannot confirm that the assumption of variances being same across time periods is not violated. In order to further explore the existence of significant differences between the three dynamicity indicators, we use the simnova function in Stata as well as conduct Bonferroni, Scheffe and Sidak multiple comparison mean tests. These tests' results, which are available from the authors upon request, confirm the mean difference between dynamicity distributions for the selected years.

\section{DISCUSSION AND CONCLUDING REMARKS}

According to extant research, dynamicity can track the evolution of a network by assessing the contribution of each network member in the overall structural dynamics. Furthermore, this measure can capture actor's behavior from a dynamicity perspective with critical events such as organizational crisis, being the culprit of network evolution changes. In this context, the focus is given towards an endogenous shock causing an effect on actor's dynamicity in a given network inside the organization. While this approach is sound, we think it could be enhanced by including the impact that critical exogenous events originating outside the organization have not only on the organization itself, but on every member to which this organization is connected to. Specifically, there seems to be little research on the effect that the global financial crisis of 2007-2008 and its subsequent recessions have on any given industry.

This paper aims to fill this gap by analyzing the effect of both crisis and recessions on organizational dynamic embeddedness evolution, focusing on strategic transactions of the global pharmaceutical industry from an actorlevel approach. We do this by plotting average firm's dynamic embeddedness evolution, analyzing dynamicity stability over the study period, listing the most important firms in the global pharmaceutical industry according to their dynamicity ranking, and testing the global and local crisis effect on firm's dynamicity. Results on firm's dynamic embeddedness suggest that prior to the global crisis the global pharmaceutical industry has been relatively stable, with firms' centrality reflecting their market position. Specifically, top pharmaceutical firms that rank high in terms of sales have a noticeable central position in both the core and full networks. This is observable in the plotting of average degree dynamicity but less so for betweenness and closeness measures, suggesting that brokerage and proximity are more volatile indicators of dynamic embeddedness. Looking at top firm rankings, we observe that even though firms from different industrial backgrounds (i.e., biotechnology, pharmaceutical, and chemical) enter the global pharmaceutical industry, key players remain the same throughout the whole study period. This behavior indicates little dynamics as far as new players is concerned probably due to big pharmaceuticals' powerful hub effect on sub-networks made of subsidiary firms, private and public institutions with whom they presumably have a long tradition of strategic collaboration.

The type of network greatly affects the centrality rankings of dynamicity, with smaller firms reducing their proximity to each-other while increasing their intermediary (i.e., brokerage) role in the core network, and bigger firms maintaining their hegemony over the whole full network as a possible result of their collaborations with subsidiaries and other private entities. More importantly, the overall general trend for all dynamicity indicators shows that the global pharmaceutical industry has reduced its activity to even lower levels than the beginning of our sampling data, year 1991. While the reduction effect varies for specific centrality measures, its effect is more prominent after 2007, which coincides with the offset of the global financial crisis of 2007-2008. From there, dynamic embeddedness deteriorates further, potentially aided by the great recession of 2008-2009 and the more local Eurozone recession of 2011-2012. Regression results confirm this by showing significant dynamicity reduction during both crises. This significance is stronger for closeness dynamicity but consistent for all dynamicity measures. Furthermore, regression results indicate that Eurozone recession has had a far deeper negative effect on global pharmaceutical industry than the great recession. One possible explanation could be that being so close to each-other, the negative effect of the more local Eurozone recession might have been augmented by the previous great recession. In fact, during our robustness analysis check not shown in this paper but available upon request, we observe that 2010, considered a recovery year, has no negative effect on dynamicity. This confirms a double-dip pattern behavior for both recessions. Moreover, the crises effect is noticeable in full networks as well, as significant mean differences among prefinancial and postfinancial crisis period are observed. Regression results also confirm the impact that financial measures such as profitability and financial leverage have on dynamicity. In particular, the more profitable and leveraged a pharmaceutical firm is, the higher the tendency to grow its proximity from other firms, a conclusion which is in line with the top firms' ranking analysis.

Our study highlights the importance of acquisition transactions in the expansion of the firms' importance as 
central hubs. Specifically, the significant effect of acquisitions on degree dynamicity demonstrates the different impact that strategic transactions have on centrality indicators and further reinforces the reasoning behind our choice to study centrality measures evolution through dynamicity conceptualization. However, this also raises questions as to why comparable effects of strategic transaction types (i.e., acquisitions and financings) respond differently to centrality-based dynamicity. One explanation could be the nature of acquisition transactions allowing a particular actor to enlarge its existing ties by including those of the newly acquired actor which does not exist anymore as an independent entity. Simply put, the firm will have more transactions when it acquires another firm since the latter's transactions will be incorporated to the former. This may not be necessarily true for brokerage or proximity reasons; throughout the study, we observe that bigger firms tend to be selective in their brokerage role and more interestingly distance themselves from smaller firms.

The study enhances existing knowledge on dynamic social networks by presenting theory-based hypotheses for testing, and validating the concept of dynamicity. We emphasize our study's precision in describing critical events which include not only endogenous perturbations such as organizational crisis $[5,70]$ but also exogenous critical events such as the global financial crisis of 2007-2008 and the subsequent recessions affecting global industries. Specifically, we show how each firm's dynamicity tracks the evolution of actor's structural embeddedness as well as ranking the contribution of each actor's centrality footprint. In this context, we observe that dynamicity can successfully be combined with the network concept of structural embeddedness by analyzing the evolution of actor-level centrality measures, thus unifying these concepts under the singular theoretical framework of dynamic embeddedness. By considering both top firms and especially their ego-network (i.e., networks in which they participate) partners, our study gives an enhanced view of the global pharmaceutical industry dynamics. Additionally, it contributes to the research on strategic collaborations, by considering the multiple impacts of alliances, acquisitions and financing transactions on the global pharmaceutical network. From the practical point of view, this study is a novel approach to the analysis of a highly convoluted industry such as the pharmaceuticals. By tracing its evolution on global perspectives, we shed light on industry's key players as well as highlight the movement of smaller firms on the overall network structure. Moreover, our results show the true impact of both global and more regional recession effects on the pharmaceutical network, suggesting the importance and at the same time fragility of strategic transactions toward exogenous perturbations of critical nature.

Our study's limitations could potentially provide interesting areas of future research. First, we should be careful when generalizing our results about the global pharmaceutical industry, knowing that not all firms in both core and periphery networks are dedicated to pharmaceuticals but come from other adjacent industries such as biotechnology and chemicals. In this light, a study across industries using bimodal network analysis could be beneficial to uncover the crisis effect on dynamic embeddedness. Second, dynamicity measure calculation is based on a novel design which takes into account missing actors during network evolution using a specific constant. However, the use of this constant is subject to further research to properly assign to it more robust values. Third, it could be interesting to test our results using traditional network measures and see whether the dynamic effect captured by dynamicity is present or not. Fourth, due to the availability of the data, we could not test for causality inferences as this would have involved the inclusion of robust instrumental variables that we did not have at our disposal. Finally, the dynamicity measure could be expanded to consider other centrality measures (i.e., Eigenvector, Bonacich Power) or be included in the analysis of network measures such as actor's structural similarity, structural holes and brokerage elasticity.

\section{ACKNOWLEDGMENTS}

The author wishes to acknowledge the financial support provided by the Spanish Ministry of Science and Education under projects ECO2010-21393-C04-01, ECO2010-21393-C0403, ECO2013-48496-C4-2-R and ECO2013-48496-C4-4-R.

\section{REFERENCES}

1. Afuah, A. Are network effects really about size? The role of structure and conduct. Strat Manage J 2012, 34(3), $257-273$.

2. Ahuja, G.; Polidoro Jr., F; Mitchell, W. Structural homophily, or social asymmetry? The formation of alliances by poorly embedded firms. Strat Manage J 2009, 30(9), 941-958.

3. Ahuja, G. Collaboration networks, structural holes, and innovation: A longitudinal study. Admin Sci Q 2000, 45(3), 425-455.

4. Andersson, U.; Forsgren, M.; Holm, U. The strategic impact of external networks: Subsidiary performance and competence development in the multinational corporation. Strat Manage J 2002, 23(11), 979-996.

5. Arya, B.; Lin, Z. Understanding collaboration outcomes from an extended resource-based view perspective: The roles of organizational characteristics, partner attributes, and network structures. J Manage 2007, 33(5), 697-723.

6. Barrat, A.; Barthelemy, M.; Pastor-Satorras, R.; Vespignani, A. The architecture of complex weighted networks. Nat Acad Sci 2004, 101(11), 3747-3752. 
7. Baum, J.A.C.; Calabrese, T.; Silverman, B.S. Don't go it alone: Alliance network composition and startups' performance in Canadian biotechnology. Strat Manage J 2000, 21(3), 267-294.

8. Berger, S.; Hinz, O. The Impact of Social Networks on Inter-Organizational Effectiveness-The Case of IPO Deal Networks. European Conference on Information Systems (ECIS): Galway, Ireland, 2008.

9. Bignoux, S. Short-term strategic alliances: A social exchange perspective. Manage Decis 2006, 44(5), $615-627$.

10. Borgatti, S.P.; Foster, P.C. The network paradigm in organizational research: A review and typology. J Manage 2003, 29(6), 991-1013.

11. Borges, C.; Filion, L.J. Spin-off Process and the development of academic entrepreneur's social capital. J Technol Manage Innovat 2013, 8(1), 21-34.

12. Brandes, U.; Lerner, J.; Snijders, T.A.B. Networks evolving step by step: Statistical analysis of dyadic event data. Adv Soc Netw Analy Min 2009, 200-205, doi: 10.1109/ASONAM.2009.28.

13. Braha, D.; Bar-Yam, Y. From centrality to temporary fame: Dynamic centrality in complex networks. Complexity 2006, 12(2), $59-63$.

14. Brass, D.J.; Galaskiewicz, J.; Greve, H.R.; Tsai, W. Taking stock of networks and organizations: A multilevel perspective. Acad Manage J 2004, 47(6), 795-817.

15. Breusch, T.S.; Pagan, A.R. The Lagrange multiplier test and its application to model specification in econometrics. Rev Econ Stud 1980, 47(1), 239-253.

16. Brunt, G.G.; Groenewegen, P. An actor-oriented dynamic network approach. The case of interorganizational network evolution. Organ Res Meth 2007, 10(3), 463-482.

17. Buchmann, T.; Pyka, A. The evolution of innovation networks: The case of a publicly funded German automotive network. Econ Innovat New Technol, 24(1-2), 114-139.

18. Burk, W.; Kerr, M.; Stattin, H. The co-evolution of early adolescent firnedship networks, school involvement, and delinquent behaviors. Revue Francaise de Sociologie 2008, 49(3), 499-522.

19. Burt, R.S. Structural Holes: The Social Structure of Competition; Harvard University Press: Cambridge, MA, 1992.

20. Butts, C.T Social network analysis: A methodological introduction. Asian J Soc Psychol 2008, 11, 13-41.

21. Carlsson, S.A. Knowledge managing and knowledge management systems in inter-organizational networks. Knowl Process Manage 2003, 10(3), 194-206.

22. Clarke, S.; Roome, N. Sustainable business: Learning-action networks as organizational assets. Bus Strat Environ 1999, 8(5) $296-310$.

23. Cravens, D.W.; Piercy, N.F; Shipp, S.H. New organizational forms for competing in highly dynamic environments: The network paradigm. Br J Manage 1996, 7(3), 203-218.

24. Dacin, M.T.; Oliver, C.; Roy, J.-P. The legitimacy of strategic alliances: An institutional perspective. Strat Manag J 2007, 28(2), $169-187$.

25. Das, T.K.; Teng, B-S. Alliance constellations: A social exchange perspective. Acad Manage Rev 2002, 27(3), $445-456$.

26. Demirkan, I.; Demirkan, S. Network characteristics and patenting in biotechnology, 1990-2006. J Manage 2012, 38(6), $1892-1927$.

27. De Montis, A.; Barthelemy, M.; Chessa, A.; Vespignani, A. The structure of Inter-Urban traffic: A weighted network analysis. Phys Soc 2005, doi: 10.1068/b32128.

28. Dittrich, K.; Duysters, G. Networking as a means to strategy change: The case of open innovation in mobile telephony. Prod Innovat Manage 2007, 24(6), 510-521.

29. Fagiolo, G.; Reyes, J.; Schiavo, S. The evolution of the world trade web: A weighted network analysis. J Evol Econ 2010, 20(4), 479-514.

30. Fabac, R.; Schatten, M.; Duricin, T. Social network mixing patterns in mergers and acquisitions-A simulation experiment. Bus Syst Res 2011, 2(1), 36-44.

31. Faust, K. Centrality in affiliation networks. Soc Networks 1997, 19(2), 157-191.

32. Fenn, D.J.; Porter, M.A.; McDonald, M.; Williams, S.; Johnson, N.F; Jones, N.S. Dynamic communities in multichannel data: An application to the foreign exchange market during the 2007-2008 credit crisis. Chaos: Interdiscip J Nonlinear Sci 2009, 19(3), 033119.

33. Fogel, J.; Nehmad, E. Internet social network communities: Risk taking, trust, and privacy concerns. Comput Hum Behav 2009, 25(1), 153-160.

34. Freeman, L. The gatekeeper, pair-dependency, and structural centrality. Qual Quant 1980, 14(4), 585-592.

35. Gilsing, V.; Nooteboom, B.; Vanhaverbeke, W.; Duysters, G.; van den Oord, A. Network embeddedness and the exploration of novel technologies: Technological distance, betweenness centrality and density. Res Pol 2008, 37(10), 1717-1731.

36. Giuliani, E. Network dynamics in regional clusters: The perspective of an emerging economy. Papers in Evolutionary Economic Geography 2010, http://econ.geo.uu.nl/peeg/peeg1014.pdf.

37. Gnyawali, D.R.; Madhavan, R. Cooperative networks and competitive dynamics: A structural embeddeness perspective. Acad Manage Rev 2001, 26(3), 431-435.

38. Granovetter M.S. Problems of explanation in economic sociology. In: Networks and Organizations; Nohria, N.; Eccles, R.G., Eds.; Harvard Business School, Press: Boston, MA, 1992, 25-56.

39. Gull, K.C.; Angadi, A.B.; Malagi, K.B. Framework for analysis of dynamic social networks evolution. Int J Eng Sci 2012, 1(2), 2319-1813.

40. Gulati, R. Network location and learning: The influence of network resources and firm capabilities on alliance formation. Strat Manag J 1999, 20(5), 397-420. 
41. Gulati, R.; Gargiulo, M. Where do interorganizational networks come from? Am J Soc 1999, 104(5), 1396-1438.

42. Gulati, R.; Nohria, N.; Zaheer, A. Strategic networks. Strat Manag J 2000, 21(3), 203-215.

43. Hagedoorn, J.; Roijakkers, N.; Van Kranenburg, H. Inter-firm R\&D networks: The importance of strategic network capabilities for high-tech partnership formation. Br J Manage 2006, 17(1), 39-53.

44. Hale, G. Bank relationships, business cycles, financial crises. J Int Econ 2012, 88(2), 312-325.

45. Havila, V.; Salmi, A. Network perspective on international mergers and acquisitions: What more do we see? In: Critical Perspectives on Internationalisation; Havila, V.; Forsgren, M.; Håkansson, H., Eds.; Pergamon: Oxford, 2002.

46. Hill, S.A.; Braha, D. Dynamic model of time-dependent complex networks. Phys Rev 2010, 82(4), 046105

47. Hoffmann, W.H. Strategies for managing a portfolio of alliances. Strat Manag J 2007, 28(8), 827-856.

48. Holland, P.W.; Leinhard, S. Structural implications of measurement error in sociometry. J Math Soc 1973, 3(1), 85-111.

49. Hossain, L.; Murshed, S.T.; Uddin, S. Communication network dynamics during organizational crisis. J Informet 2013, 7(1), $16-35$.

50. Inkpen, A.C.; Tsang, E.W.K. Social capital, networks, and knowledge transfer. Acad Manage Rev 2005, 30(1), $146-165$.

51. Karamanos, A.G. Leveraging micro- and macro-structures of embeddedness in alliance networks for exploratory innovation in biotechnology. R\&D Manage 2012, 42(1), 71-89.

52. Kim, M.; Leskovec, J. Nonparametric multi-group membership model for dynamic networks. Adv Neural Inform Process Syst 2013, arXiv:1311.2079.

53. King, M.R.; Santor, E. Family values: Ownership structure, performance and capital structure. J Bank Fin 2008, 32(11), $2423-2432$.

54. Koka, B.R.; Prescott, J.E. Strategic alliances as social capital: A multidimensional view. Strat Manag J 2002, 23(9), $795-816$.

55. Koka, B.R.; Prescott, J.E. Designing alliance networks: The influence of network position, environmental change, and strategy on firm performance. Strat Manag J 2008, 29(6), 639-661.

56. Kossinets, G.; Watts, D. Empirical analysis of an evolving social network. Science 2006, 311(5757), 88-90.

57. Kossinets, G. Effects of missing data in social networks. Soc Network 2006, doi:10.1016/j.socnet.2005.07.002.

58. Kuzubas, T.U.; Ömercikglu, I.; Saltoglu, B. Network centrality measures and systemic risk: An application to the Turkish financial crisis. Phys A Stat Mech Appl 2014, 405, 203-215.

59. Landherr, A.; Friedl, B.; Heidemann, J. A critical review of centrality measures in social networks. Bus Information Syst Eng 2010, 2(6), 371-385.

60. Latapy, M.; Magnien, C.; Del Vecchio, N. Basic notions for the analysis of large two-mode networks. Soc Network 2008, 30(1), 31-48.

61. Lin, Z.; Peng, M.W.; Yang, H.; Sun, S.L. How do networks and learning drive M\&As? An institutional comparison between China and the United States. Strat Manag J 2009, 30(10), 1113-1132.

62. Loderer, C.; Waelchli, U. Firm age and performance. Working paper, University of Bern. 2010. http://dx.doi.org/10.2139/ ssrn.1342248.

63. Lubbers, M.J.; Molina, J.L.; Lerner, J.; Brandes, U.; Ávila, J.; McCarty, C. Longitudinal analysis of personal networks. The case of Argentinian migrants in Spain. Soc Network 2010, 32, 91-104.

64. Madhavan, R.; Koka, B.R.; Prescott, J.E. Networks in transition: How industry events (re)shape interfirm relationships. Strat Manag J 1998, 19(5), 439-459.

65. Minoiu, C.; Reyes, J.A. A network analysis of global banking: 1978-2010. J Fin Stab 2013, 9(2), 168-184.

66. Moran, P. Structural vs. relational embeddedness: Social capital and managerial performance. Strat Manag J 2005, 26(12), 1129-1151.

67. Nahapiet, J.; Ghoshal, S. Social capital, intellectual capital, and the organizational advantage. Acad Manage Rev 1998, 23(2), $242-266$.

68. Newman, M.E.J. Analysis of weighted networks. Phys Rev 2004, 70(5), 056131.

69. Nobi, A.; Maeng, S.E.; Ha, G.G.; Lee, J.W. Effects of global financial crisis on network structure in a local stock market. Phys A Stat Mech Appl 2014, 407, 135-143.

70. Opsahl, T.; Colizza, V.; Panzarasa, P;; Ramasco, J.J. Prominence and control: The weighted rich-club effect, 2008, doi. 10.1103/PhysRevLett.101.168702.

71. Opsahl, T.; Hogan, B. Growth mechanisms in continuously-observed networks: Communication in a Facebook-like community, 2011, doi: arXiv:1010.2141.

72. Opsahl, T.; Agneesens, F; Skvoretz, J. Node centrality in weighted networks: Generalizing degree and shortest paths. Soc Network 2010, 32(3), 245-251.

73. Ouzienko, V.; Obradovic, Z. Imputation of missing links and attributes in longitudinal social surveys. Mach Learn 2014, 95(3), 329-356.

74. Robins, G.; Pattison, P.; Kalish, Y.; Lusher, D. An introduction to exponential random graph (p*) models for social networks. Soc Network 2007, 29(2), 173-191.

75. Snijders, T. Stochastic actor-oriented models for network change. J Math Soc 1996, 21, 149-172.

76. Snijders, T. The statistical evaluation of social network dynamics. Soc Method 2001, 31(1), 361-365.

77. Snijders, T.A.B. Statistical models for social networks. Ann Rev Soc 2011. doi: 10.1146/annurev.soc.012809.102709.

78. Stuart, T.E. Network positions and propensities to collaborate: An investigation of strategic alliance formation in a hightechnology industry. Admin Sci Q 1998, 43(3), 668-698.

79. Takaffoli, M.; Sangi, F.; Fagnan, J.; Zaïnane, O.R. Community evolution mining in dynamic social networks. Procedia - Soc Behav Sci 2011, doi:10.1016/j.sbspro.2011.07.055. 
80. Täube, V.G. Measuring the social capital of brokerage roles. Connections 2003, 26(1), 29-52.

81. Uddin, S.; Chung, K.S.K.; Piraveenan, M. Capturing Actor-level Dynamics of Longitudinal Networks. ASONAM '12 Proceedings of the 2012 International Conference on Advances in Social Networks Analysis and Mining, 2012, doi: 10.1109/ ASONAM.2012.175.

82. Uddin, S.; Piraveenan, M.; Khan, A.; Amiri, B. Conceptual quantification of the dynamicity of longitudinal social networks. SocialCom 2013, 868-873, doi: 10.1109/SocialCom.2013.131.

83. Uddin, S.; Khan, A.; Piraveenan, M. A set of measures to quantify the dynamicity of longitudinal social networks. Complexity 2015, http://onlinelibrary.wiley.com/doi/10.1002/cplx.21690/epdf.

84. Uzzi, B. Social structure and competition in interfirm networks: The paradox of embeddedness. Admin Sci Q 1997, 42(1), 35-67.

85. Van de Bunt, G.G.; Van Duijn, M.A.J.; Snijders, T.A.B. Friendship networks through time: An actor-oriented dynamic statistical network model. Comput Math Organ Theory 1999, 5(2), 167-192.

86. Wasserman, S.; Faust, K. Social Network Analysis: Methods and Applications; Cambridge University Press, 1994.

87. Welch, I. Two common problems in capital structure research: The financial-debt-to-asset ratio and issuing activity versus leverage changes. Int Rev Fin 2011, 11(1), 1-17.

88. Whittington, K.B.; Owen-Smith, J.; Powell, W.W. Networks, propinquity, and innovation in knowledge-intensive industries. Admin Sci Q 2009, 54(1), 90-122.

89. Yang, H.; Lin, Z(J).; Peng, M.W. Behind acquisitions of alliance partners: Exploratory learning and network embeddedness. Acad Manage J 2011, 54(5), 1069-1080.

90. Zaheer, A.; Hernandez, E.; Banerjee, S. Prior alliances with targets and acquisition performance in knowledge-intensive industries. Organ Sci 2010, 21(5), 1072-1091. 